\title{
Decay Scheme of ${ }^{118}$ In $(4.45 \mathrm{~min})$
}

\author{
L. C. M. do Amaral, C. V. de Barros Leite, J. M. F. Jeronymo, and A. G. De Pinho \\ Department of Physics, P.U.C., Rio de Janeiro \\ and D. Russo and S. DE Barros \\ Centro Brasileiro de Pesquisas Fisicas, Rio de Janeiro, Brasil \\ (Z. Naturforsch. 24 a, 1196-1202 [1969]; received 5 May 1969)
}

\begin{abstract}
The energies and relative intensities of the $\gamma$-radiation following the decay of the $4.45 \mathrm{~min}$ isomer of ${ }^{118} \mathrm{In}$ have been measured using a $\mathrm{Ge}(\mathrm{Li})$ detector. A total of sixteen $\gamma$-rays was observed of which six for the first time. A decay scheme ist presented and discussed; it incorporates fifteen of the observed transitions.
\end{abstract}

\section{Introduction and Experimental Techniques}

The level structure of the even mass isotopes of tin has been intensively investigated in the recent past by means of nuclear transfer reactions ${ }^{1}$, nuclear scattering ${ }^{2}$ or Coulomb excitation ${ }^{3}$. This increasing interest is due, at least in part, to some successful calculations of the nuclear properties of the double and single closed shell nuclei. Following a suggestion of BoHr et al. ${ }^{4}$ of applying the theory of superconductivity to the nuclear structure, KIssIINGER and SORENSEN ${ }^{5}$ and later ARVIEU et al. ${ }^{6}$ have performed systematic comparisons between the experimental level schemes and the predictions of the pairing model. Some shell model calculations of the even mass isotopes of tin have been published recently ${ }^{7,8}$.

Although the more relevant features of the decay of the high spin isomer of ${ }^{118}$ In have been established by KANTELE and KARRAs ${ }^{9}$, some difficulties are apparent in their proposed decay scheme as for instance the non-observation of some expected tran-

Reprints requests to Pontificia Universidade Católica do Rio de Janeiro, Instituto de Física, Rua Marquês de São Vicente, 225, Gávea-GB., Rio de Janeiro-Zc-20, Brasil.

1 J. H. Bjerregaard, O. Hansen, O. Nathan, L. Vistisen, R. Chapman, and S. Hinds, Nucl. Phys. A-110, 1 [1968]. - E. J. Schneid, A. Prakash, and B. L. Cohen, Phys. Rev. 156, 1316 [1967]. - L. Norris and C. F. Moore, Phys. Rev. 136, B 40 [1964]. - G. E. Holland, C. A. Whitten, J. Maher, and D. A. Bromley, Contribution 8-81 to the Intern. Conf. on Nuclear Structure, Tokyo, Japan, 1967.

2 D. L. Allan, B. H. Armitage, and B. A. Doran, Nucl. Phys. 66, 481 [1965]. - N. Baron, R. F. LeONARD, John L. Need, W. M. Stewart, and V. A. Madsen, Phys. Rev. 146, 861 [1966]. - Y. S. KIn and B. L. Cohen, Phys. Rev. 142, 788 [1966].

3 R. L. Robinson, P. H. Stelson, F. K. McGowan, J. L. C. Ford, and W. T. Milner, Nucl. Phys. 74, 281 [1965]. sitions. We reinvestigated the decay of this isomer in order to determinate more accurately the energies and intensities of the gamma transitions.

Enriched ${ }^{119} \mathrm{Sn}$ targets (Chemical form: $\mathrm{SnO}_{2}$; enrichment up to $95.8 \%$; delivered by Oak Ridge Nat. Lab., Isotope Sales Dept.) were irradiated by the bremsstrahlung beam from the C.B.P.F. linear accelerator at an electron energy ob about $22 \mathrm{MeV}$. The ${ }^{118} \mathrm{In}$ was produced by $(\gamma, \mathrm{p})$ reaction. After allowing the decay of the $5 \mathrm{sec}$ isomer the $\gamma$ spectrum was detected by a $2 \mathrm{~cm}^{3} \mathrm{Ge}(\mathrm{Li})$ diode and displayed on a 4096-channel Intertechnique analyser. The system was calibrated in energy and efficiency with the ${ }^{56} \mathrm{Co}$ and other standard radioactive sources ${ }^{10}$. The full width at half-maximum for the photopeaks of the ${ }^{60} \mathrm{Co} \gamma$-rays was of $4 \mathrm{keV}$.

\section{Results}

Fiften $\gamma$-rays were observed decaying with a halflife of $(4.45 \pm 0.05) \mathrm{min}$. The ten most prominent peaks identified by KANTEle and $\mathrm{Karras}^{9}$ were

4 A. Bohr, B. R. Mottelson, and D. Pines, Phys. Rev. 110, 936 [1958].

5 L. S. Kisslinger and R. A. Sorensen, Kgl. Danske Videnskab. Selskab, Mat. Phys. Medd. 32, No 9 [1960].

6 R. Arvieu, E. Baranger, M. Veneroni, M. Baranger, and V. Gillet, Phys. Letters 4, 119 [1963]. - R. Arvieu, Thèse, Université de Paris 1963; Ann. Phys. Paris 8, 407 [1963].

7 M. Gmitro, J. Hendekovic, and J. Sawicki, Phys. Rev. 169, 983 [1968]. - M. Gmitro, A. Rimini, J. SAwicki, and T.Weber, Phys. Rev. 173, 964 [1968]. - R. Alzetta and J. SAWICKI, ICTP, preprint IC/68/33 [1968].

8 D. M. Clement and E. Baranger, Nucl. Phys. A 120, 25 [1968].

9 J. Kantele and M. Karras, Phys. Rev. 135, B 9 [1964].

10 J. B. Marion, Nuclear Data, Section A, 4, 301 [1968]. 


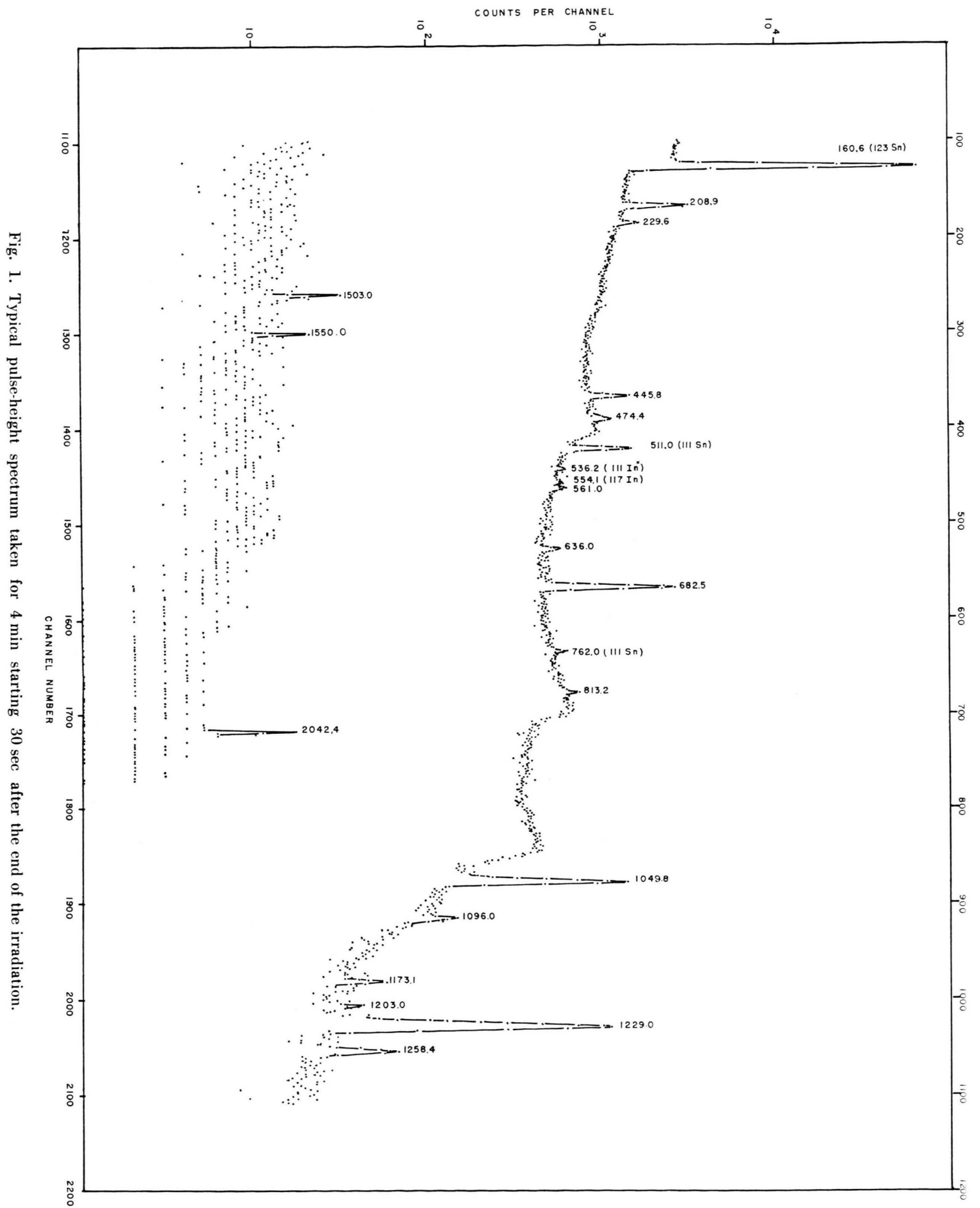


confirmed and five new transitions that fit well the level scheme were identified. In only one or, at most, in two spectra (those of best statistics) of the nine independent spectra analysed we found some evidence for two $\gamma$-rays given as uncertain by those authors, namely, the $1550 \mathrm{keV}$ and the $1733 \mathrm{keV}$ trasitions. A transition of $1203 \mathrm{keV}\left(l_{\gamma}<1.2\right)$ was also observed in a few spectra and it decays with a short half-life. We are not sure whether it pertains to the decay scheme of ${ }^{118} \mathrm{In}$. The energies and intensities obtained in this work are reported in Table 1. A typical observed $\gamma$ spectrum is shown in Fig. 1.

\begin{tabular}{|c|c|c|}
\hline \multirow{2}{*}{$\begin{array}{c}\text { Energie } \\
\text { keV }\end{array}$} & \multicolumn{2}{|c|}{$\gamma$-Rays Intensities } \\
\hline & $\begin{array}{c}\text { KANTELE and } \\
\text { KARRAS }^{9}\end{array}$ & $\begin{array}{l}\text { Present } \\
\text { Work }\end{array}$ \\
\hline $208.9 \pm 0.8$ & $3.0 \pm 1.5$ & $3.7 \pm 0.3$ \\
\hline $229.6 \pm 1.0$ & - & $1.1 \pm 0.2$ \\
\hline $445.8 \mp 0.6$ & $7 \pm 2$ & $5.9 \mp 0.5$ \\
\hline $474.4 \pm 0.8$ & - & $3.4 \pm 0.4$ \\
\hline $561.0 \pm 1.2$ & - & $1.7 \pm 0.4$ \\
\hline $636.0 \mp 1.0$ & $\approx 10$ & $2.7 \mp 0.5$ \\
\hline $682.5 \pm 0.5$ & \pm 8 & $50.3 \pm 4.7$ \\
\hline $813.2 \pm 0.6$ & $7 \pm 2$ & $4.3 \mp 1.0$ \\
\hline $1049.8 \pm 0.3$ & $83 \pm 6$ & $81.0 \pm 4.2$ \\
\hline $1096.0 \pm 1.0$ & 二 & $4.5 \mp 0.9$ \\
\hline $1173.1 \pm 0.9$ & - & $2.1 \pm 0.5$ \\
\hline $1203 \pm 1$ & - & $\leqq 1.2$ \\
\hline $1229.0 \pm 0.3$ & 100 & $100.0 \neq 5.2$ \\
\hline $1258.4 \pm 0.4$ & $6 \pm 2$ & $4.5 \pm 1.0$ \\
\hline $1503.0 \pm 0.8$ & $1.4 \pm 0.4$ & $2.0 \pm 0.5$ \\
\hline $1550 \pm 1$ & $1.0 \pm 0.4$ & $\leqq 1.0^{-}$ \\
\hline $1733 \pm 1$ & $\approx 0.4$ & $\leqq 0.6$ \\
\hline $2042.4 \pm 1.0$ & $3.1 \pm 0.6$ & $2.6 \pm 0.5$ \\
\hline
\end{tabular}

Table 1. Energies and intensities of the $\gamma$-rays found in the decay of ${ }^{118} \mathrm{In}(4.45 \mathrm{~min})$. Intensities are arbitrarily normalized to $I_{\gamma}(1229 \mathrm{keV})=100$.

The resulting decay scheme is given in Fig. 2. A new level at $2.403 \mathrm{MeV}$ is included. It is probably the same level observed by BJERREGAARD et al. ${ }^{1}$ by $(t, p)$ reaction at about the same energy and by inelastic scattering of protons and deuterons ${ }^{2}$. A level at $2.779 \mathrm{MeV}$, not observed in any nuclear reactions experiments, was suggested in ref. ${ }^{9}$ to accommodate the $1550 \mathrm{keV}$ transition. Since this transition is neither confirmed nor rejected by our results this level is represented by a broken line in the decay scheme.

11 R. A. Broglia, C. Riedel, B. Sorensen, and T. Udagawa, Nucl. Phys. A 115, 273 [1968].

12 H. H. Bolotin, A. C. Li, and A. Schwarzschild, Phys. Rev. 124, 213 [1961].
Beside an extremely weak $1733 \mathrm{keV}$ cross-over transition, a total of five cascades were found deexciting the $2962.3 \mathrm{keV}$ level. This level, given as $4^{+}$, is particularly interesting since it is fed by the beta branch that presents the lesser value of $\log f t$. These cascades are:

$$
\begin{aligned}
& 229.6 \mathrm{keV}+1503.0 \mathrm{keV}, \\
& 474.4 \mathrm{keV}+1258.4 \mathrm{keV}, \\
& 561.0 \mathrm{keV}+1173.1 \mathrm{keV}, \\
& 682.5 \mathrm{keV}+1049.8 \mathrm{keV}
\end{aligned}
$$

(the most intense)

and

$$
636.0 \mathrm{keV}+1096.0 \mathrm{keV} .
$$

The end of the cross-over and of the five cascades is the first excited state at $1229.0 \mathrm{keV}$. Concerning the last cascade it is worth noting that a very difficult problem arises in the interpretation of the intermediate level. The existence of a doublet of odd parity levels around $2.32 \mathrm{MeV}$ is commonly admitted ${ }^{11}$. The $3^{-}$state is a very collective one and is observed by inelastic scattering or Coulomb excitation. The $5^{-}$state, on the other hand, is almost a pure two-quasi-particle excitation. This state is of the same type as the $7^{-}$state observed in the decay of the $5 \mathrm{~h}$ isomer of ${ }^{118} \mathrm{Sb}$. In the ${ }^{116} \mathrm{Sn}$ the levels $3^{-}, 5^{-}$and $7^{-}$were also identified ${ }^{12}$, but the $3^{-}$and $5^{-}$levels are $100 \mathrm{keV}$ apart. These levels are not directly fed by the $\beta$ decay of the $54 \mathrm{~min}$ isomer of ${ }^{116} \operatorname{In}{ }^{13}$.

The presence of the above mentioned cascade implies that either the $3^{-}$level or the $5^{-}$level are populated via the $4^{+}$state at $2962.3 \mathrm{keV}$ or even directly populated by $\beta$ decay since the intensity of the $1096.0 \mathrm{keV}$ transition is slightly larger than the intensity of the $636.0 \mathrm{keV}$ transition. The decay of the $5^{-}$state, as observed in the desintegration of ${ }^{118} \mathrm{Sb}$, proceeds mainly by a $40 \mathrm{keV}$ transition to the first $4^{+}$excited state. A systematic search was made to identify a $\gamma$ ray in the range from 30 to $50 \mathrm{keV}$. A $6 \mathrm{~mm} \mathrm{NaI}(\mathrm{Tl})$ crystal was employed for this purpose with negative results. So, it seems that the level involved in the cascade is the $3^{-}$state although, as will be discussed in the next section, such choice is far from settling all the problems.

13 N. L. Da Costa, C. V. de Barros Leite, A. G. De Pinho, D. Goldman, Y. Miyao, and I. C. Nascimento, Nuovo Cimento (X), 50, 345 [1967]. 


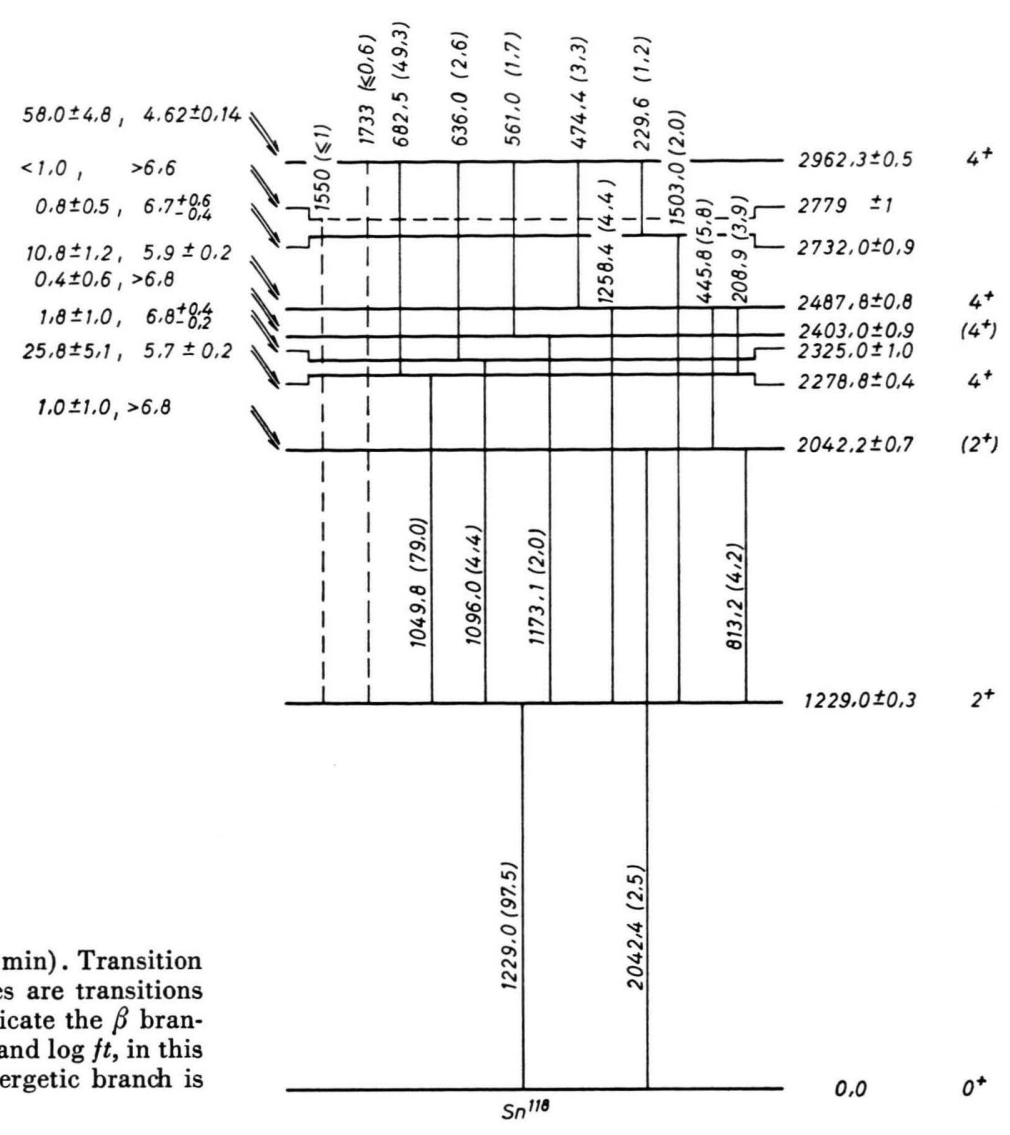

Fig. 2. Proposed decay scheme of ${ }^{118} \mathrm{In}$ (4.45 min). Transition energies are given in $\mathrm{keV}$ and the intensities are transitions per 100 decays. The small arrows at left indicate the $\beta$ branches and the numbers are relative intensities and $\log f t$, in this order. The maximum energy of the most energetic branch is (2.0 \pm 0.1$) \mathrm{MeV}^{9}$.

\section{Discussion of the Results}

The $\mathrm{g} 9 / 2$ proton hole occurs systematically as the ground state of the odd mass isotopes of In, the $\mathrm{p}^{1 / 2}$ hole being the first excited state. The isomerism in the even mass isotopes can be explained by the coupling of these proton holes with the available neutron states. The coupling of the $g^{7 / 2}$ proton hole is probably the best description of the $\mathrm{1}^{+}$isomer that occurs from ${ }^{112} \mathrm{In}$ ton ${ }^{120} \mathrm{In}$, feeding quite regularly the ground $\left(0^{+}\right)$and first excited $\left(2^{+}\right)$ states of the even isotopes of Sn. In the ${ }^{114,116} \mathrm{In}$ isotopes the spin of the other isomeric state was measured ${ }^{12}$ and is equal to 5 . They seem to be correctly described by the configuration $\left(\mathrm{g}^{9 / 2}\right)_{\mathrm{p}}{ }^{-1}$ $\left(\mathrm{s}^{1 / 2}\right)_{\mathrm{n}}$. This interpretation is supported by the (d,p) results ${ }^{15}$ but an admixture of $\left(\mathrm{g}^{9 / 2}\right)^{-1}\left(\mathrm{~d}^{3 / 2}\right)$ may be present as THOMPSON et al. ${ }^{16}$ concluded

14 I. Lindgren, Table of Nuclear Spins and Moments in Alpha, beta and gamma ray Spectroscopy, Ed. by K. SIEGBAHN, North-Holland Publishing Co., Amsterdam 1965. from scattering experiments in which the analogue states were observed. In ${ }^{118}$ In the spin of the 4.45 min isomer was not yet measured but it is probably 4 or 5 on the basis of the measured $\log f t$ values. It is plausible to adopt the same configuration as above for describing this state.

As in the decay of the $54 \mathrm{~min}{ }^{116} \mathrm{In}$, the decay of $4.45 \mathrm{~min}{ }^{118} \mathrm{In}$ seems to select in a very stringent way the $4^{+}$states of the daughter. As shown by ARVIEU ${ }^{6}$ these states are very complicated mixtures of two quasi-particles states. With the restriction of the diagonalization space adopted by ARVIEU these $4^{+}$states are given as mixtures of seven 2 qp states, namely: $\left(\mathrm{d}^{5 / 2}\right)^{2},\left(\mathrm{~g}^{7 / 2}\right)^{2},\left(\mathrm{~h}^{11 / 2}\right)^{2},\left(\mathrm{~d}^{5 / 2}, \mathrm{~d}^{3 / 2}\right)$, $\left(g^{7 / 2}, s^{1 / 2}\right),\left(g^{7 / 2}, d^{3 / 2}\right)$ and $\left(g^{7 / 2}, d^{5 / 2}\right)$. If we admit that the $5^{+}$state of ${ }^{118} \mathrm{In}$ is a pure $\left(\mathrm{g}^{9 / 2}\right)_{\mathrm{p}}{ }^{-1}$ $\left(\mathrm{s}^{1 / 2}\right)_{\mathrm{n}}$ state it is clear that only the $\left(\mathrm{g}^{7 / 2}, \mathrm{~s}^{1 / 2}\right)$ component of the $4^{+}$states can be reached by the

15 S. A.Hjorth and L.H.Allen, Arkiv Fysiki 33, 121 [1967]. 16 J. C. Thompson, K. Talbot, and G. Parry, Nucl. Phys. 89, 209 [1966]. 
$\beta$ decay. As pointed out by AlexandeR ${ }^{17}$, the $\beta$ decay probability can be used to explore the structure of mixed 2 qp states when only one of the components of the mixture can be excited via an allowed Gamow-Teller transition. The transition probability should be proportional to the squared amplitude $a_{i}{ }^{2}$ of this component in the given state.

The effect of interactions among the quasiparticles is to distribute a particular $2 \mathrm{qp}$ strength to the states available. The "center of gravity" of this distribution always remains at the zero order position of the 2 qp state involved. In ${ }^{120} \mathrm{Sn}$, seven $4^{+}$states have been identified and the center of gravity of the $\left(g^{7 / 2}, \mathrm{~s}^{1 / 2}\right)$ component of these states, found by the analysis of ALEXANDER ${ }^{17}$ at $3.15 \mathrm{MeV}$, is to be compared with the value of the pure 2 qp state (without residual qp interactions) calculated $^{5}$ at $3,4 \mathrm{MeV}$. In ${ }^{118} \mathrm{Sn}$ only four levels have been identified and the analysis is less complete. Nevertheless, since a very consistent picture was reached by ALEXANRER ${ }^{17}$ in the case of ${ }^{116} \mathrm{Sn}$ where only four $4^{+}$states are known ${ }^{13}$, we will apply the same method to our results concerning the ${ }^{118} \mathrm{Sn}$. It is obvious that in this case the extracted squared amplitudes are upper limits.

In Table 2 we present the $\log f t$ obtained in the $\nu \mathrm{g}^{7 / 2} \rightarrow \pi \mathrm{g}^{9 / 2}$ transition in the neighbouring oddmass nuclei, the squared amplitudes $a_{i}{ }^{2}$ of the $\left(g^{7 / 2}, s^{1 / 2}\right)$ configuration and the energy of the center of gravity. The pure 2 qp state was calculated in this case at $3.1 \mathrm{MeV}$. Following this analysis the $4^{+}$level at $2962.3 \mathrm{keV}$ is an almost pure $\left(\mathrm{g}^{7 / 2}\right.$, $\mathrm{s} 1 / 2$ ) configuration. Indeed the calculations of Arvieu show that among the four lowest $4^{+}$levels there is one level with a very large $\left(\mathrm{g}^{7 / 2}, \mathrm{~s}^{1 / 2}\right)$ amplitude. In the other $4^{+}$levels this amplitude is such that $\Sigma a_{i}{ }^{2} \lesssim 12 \%$. This configuration seems to be absent from the $2.403 \mathrm{keV}$ level. More detailed comparison is not posible since Arvieu does not give the complete set of wave functions for ${ }^{118} \mathrm{Sn}$.
The observed situation is quite different in ${ }^{116} \mathrm{Sn}$ where the four identified $4^{+}$states are fed by $\beta$ branches with comparable values of $\log f t$. On the contrary, in ${ }^{120} \mathrm{Sn}$ there is a $4^{+}$level at $3.06 \mathrm{MeV}^{9}$ populated by a low $f t \beta$ branch. This level is to be identified with the $2.963 \mathrm{MeV}$ level in ${ }^{118} \mathrm{Sn}$. Both levels decay predominantly through the first $4^{+}$level which in both cases, is not strongly populated by direct beta decay.

As has been remarked by Bolotin ${ }^{18}$ in a first comparison between the level scheme of ${ }^{116} \mathrm{Sn}$ and the predictions of the pairing-force calculations, the neglect of seniority - 4 admixtures may be probably the biggest shortcoming of the Arvieu's calculations. The $4 \mathrm{qp}$ contribution is taken into account in more recent calculations ${ }^{7}$ but only special attention is paid to levels expected to be strongly excited by nucleon transfer reactions. This is not the case of the $4^{+}$levels discussed in this work.

Our final remarks concern the $3^{-}$and $5^{-}$state Following Arvieu the wave function of the $5^{-}$state is $\quad-0.590\left|\mathrm{~s}^{1 / 2} \mathrm{~h}^{11 / 2}\right\rangle+0.806\left|\mathrm{~d}^{3 / 2} \mathrm{~h}^{11 / 2}\right\rangle$ plus some small components due to the coupling of $\mathrm{h}^{11 / 2}$ with $g^{7 / 2}$ or $d^{5 / 2}$. The $\beta$ decay from the $5^{+}$isomer to this state corresponds to the transition

$$
v\left(\mathrm{~h}^{11 / 2}\right) \rightarrow \pi\left(\mathrm{g}^{9 / 2}\right)
$$

and it should be a relatively weak transition since $\Delta l=2$. Moreover the E1 transition from the 2962.7 $\mathrm{keV}$ level to this level should be also very weak since it would proceed through very small impurities in the parent state. In the framework of Arvieu's calculations the $3^{-}$state is a mixture of $\left(h^{11 / 2}, d^{5 / 2}\right)$ and $\left(h^{11 / 2}, g^{7 / 2}\right)$ configurations. The same reasoning as before predicts very weak $\beta$ and $\gamma$ transitions from the $5^{+}$and $4^{+}$states, respectively, to the final $3^{-}$level. In particular, a $(\Delta J=2$, yes $)$ unique forbidden $\beta$ transitions is not expect with the observed value of $\log f t=6.8$. So, if the $5^{-}$value seems to be excluded by the absence of a $40 \mathrm{keV}$ transition, the $3^{-}$alternative is severely decried by

\begin{tabular}{|c|c|c|c|c|}
\hline Level (keV) & $\log f t$ & $\log \overline{f t}$ & $a_{i}^{2} \quad(\%)$ & $\sum E_{i} a_{i}^{2}$ \\
\hline $2962.3 \pm 0.5$ & $4.62 \pm 0.14$ & $\log \overline{f t}=4.57+0.15$ & 88.4 & \\
\hline $2487.8+0.8$ & $5.9+0.2$ & ${ }^{117} \mathrm{In} \rightarrow{ }^{117} \mathrm{Sn}: \log f t=4.5$ & 4.6 & $2.96 \mathrm{MeV}$ \\
\hline $2403.0+0.9$ & $>6.8$ & ${ }^{119} \mathrm{In} \rightarrow{ }^{119} \mathrm{Sn}: \log f t=4.4$ & $<0.2$ & \\
\hline $2278.8 \pm 0.4$ & $5.7 \pm 0.2$ & & 6.7 & \\
\hline
\end{tabular}

Table 2. The AleXANDER's analysis ${ }^{17}$ of the relative hindrances in the $\beta$ branches populating the $4^{+}$levels of ${ }^{118} \mathrm{Sn}$.

17 K. F. Alexander, in Nuclear Structure, Dubna Symposium, IAEA Vienna 1968, p. 15.
18 H. H. Bolotin, Phys. Rev. 136, B 1566 [1964]. 
theoretical considerations. Neither $5^{-}$nor $3^{-}$values are consistent with all the (restricted) informations we have.

\section{The Level Scheme of ${ }^{118} \mathrm{Sn}$}

There is a relatively poor overlap among all the different experimental results concerning the level scheme of ${ }^{118} \mathrm{Sn}$. This fact is due to the high selectivity of the processes involved. In this section we will try to present a general review of the situation for levels up to $3 \mathrm{MeV}$.
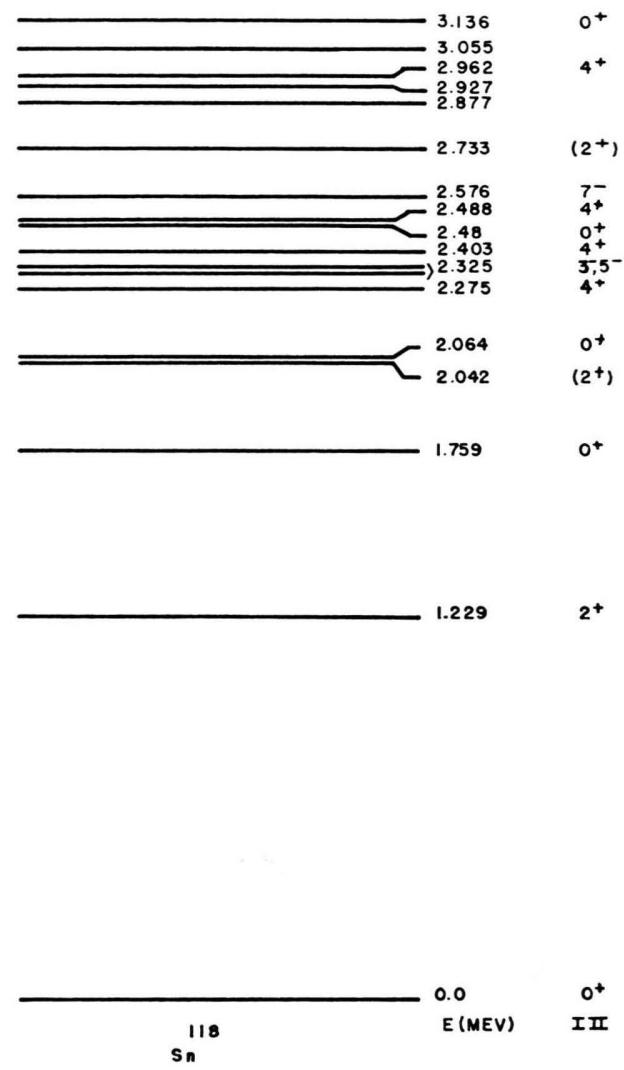

Fig. 3. The level scheme of ${ }^{118} \mathrm{Sn}$. Only levels observed by at least two groups are shown.

The first excited state is given as $2^{+}$by inelastic scattering (IS) and coulomb excitation experiments. The same assignement is consistent with $(t, p)$ and $(\mathrm{p}, \mathrm{t})$ results and decay data (refs. ${ }^{9,12}$ and present work). $\mathrm{A}^{+}$state at $1.759 \mathrm{MeV}$ was identified by BJERREgAARD et al. in $(t, p)$ experiments. It is the same level observed by Bromley et al. by $(p, t)$, by CoHen et al. by $(d, p)$ and in the decay ${ }^{9}$ of the $1^{+}$ isomer of ${ }^{118} \mathrm{Sb}$.
The results of KANTELE and KarRas ${ }^{9}$, confirmed by the present work, indicate a $2^{+}$level at 2.042 $\mathrm{MeV}$. This level does not seem to be directly fed by the $\beta$ decay of the $5^{+}$isomer of ${ }^{118} \mathrm{Sn}$. It is not observed by nuclear reactions. On the other hand, a $0^{+}$level $20 \mathrm{keV}$ higher was observed by $(\mathrm{t}, \mathrm{p})$. This level is to be identified with the $0^{+}$state at $2.05 \mathrm{MeV}$ populated by the decay of the $1^{+}$isomer of ${ }^{118} \mathrm{Sb}$. Cohen et al. and Bromley et al. reported a $0^{+}$level at the same position. Probably in many reaction data the doublet $2^{+}-0^{+}$at around $2.05 \mathrm{MeV}$ was not resolved. The existence of both levels is undoubted.

The next excited state appears at $2.279 \mathrm{MeV}$. It is given as $4^{+}$in the decay of the $5 \mathrm{~h}$ isomer of ${ }^{118} \mathrm{Sb}$. Such assignement is compatible with $(t, p)$ data and our results.

At around $2.32 \mathrm{MeV}$ we find another closely spaced doublet. In fact, a "level" at $2.32 \mathrm{MeV}$ has been reported as $3^{-}$from IS data and as $5^{-}$from decay data $\left(5 \mathrm{~h}\right.$ isomer of $\left.{ }^{118} \mathrm{Sb}\right)$. As shown by Broglia et al. the $\left(p, p^{\prime}\right)$ cross section and the $(t, p)$ cross section have the same order of magnitude as the sum of the cross section obtained separately for the $3^{-}$and $5^{-}$states in the neighbouring isotopes. This is a very strong argument supporting the hypothesis of an unresolved $\left(3^{-}, 5^{-}\right)$doublet at this energy. The $(d, p)$ data of Cohen et al. suggest that probably a $(1,2,3)^{+}$level can be present around this energy. If any of these levels is directly fed by the $4.45 \mathrm{~min}$ isomer of ${ }^{118} \mathrm{In}$ the $5^{-}$value is to be preferred but the absence of the characteristic 40 $\mathrm{keV}$ transition connecting the $5^{-}-4^{+}$levels invalidates this assumption. The problem of which level is observed in the decay studied in this work remains an open question.

A $4^{+}$state was observed by IS and $(t, p)$ at 2.40 $\mathrm{MeV}$. It is also present in our proposed decay scheme at $2.403 \mathrm{MeV}$.

Another $0^{+}$state was found at $2.48 \mathrm{MeV}$ by $(\mathrm{d}, \mathrm{p})$ reaction and in the decay of the $3.5 \mathrm{~min}{ }^{118} \mathrm{Sb}$. At about the same energy a third $4^{+}$state appears, excited in the decay of the high spin isomer of ${ }^{118} \mathrm{In}$. It is not clear which member of this doublet is excited by IS and $(t, p)$. Allan et al. suggest $0^{+}$as being the level excited by ( $\left.p, p^{\prime}\right)$.

The $7^{-}$level of ${ }^{118} \mathrm{Sn}$ appears at $2.576 \mathrm{MeV}$. It is known from the decay of ${ }^{118} \mathrm{Sb}$ ( $5 \mathrm{~h}$ isomer) and by the reaction $(t, p)$. Cohen et al. give levels at $2.54 \mathrm{MeV}$ and $2.67 \mathrm{MeV}$. If these levels exist they 
are not very probably the $7^{-}$state since a transfer with $\Delta l=7$ is not to be expected in low-energy $(\mathrm{d}, \mathrm{p})$ reactions.

The level at $2.733 \mathrm{MeV}$ is given as $2^{+}$by Cohen et al. It is also observed in the double transfer reactions. If it is direcetly fed in the decay of the $4.45 \mathrm{~min}$ isomer this would indicate a higher spin for this level. We found in this work for the 229 $\mathrm{keV}$ transition a slightly smaller intensity than for the $1504 \mathrm{keV}$ transition but no definite conclusion can be drawn.

The level at $2.78 \mathrm{MeV}$ was suggested by Kantele and Karras to accommodate a very weak $1.55 \mathrm{MeV}$ transition. There is also an indication for this transition in the present work, but it must be considered uncertain.

Levels at $2.81 \mathrm{MeV}, 2.84 \mathrm{MeV}$ and $2.86 \mathrm{MeV}$ observed by Cohen et al. where not observed in other experiments. The level given by $(\mathrm{d}, \mathrm{p})$ at $2.89 \mathrm{MeV}$ is also observed by IS and $(t, p)$. It is not observed in the decay experiments. A possible level at 2.091
$\mathrm{MeV}$ is given by the (t,p) experiment. A level at $2.927 \mathrm{MeV}$ vas observed by $(\mathrm{t}, \mathrm{p})$ and $(\mathrm{d}, \mathrm{p})$.

The level at $2962.3 \mathrm{keV}$ is the most populated in the decay of the $4.45 \mathrm{~min}$ isomer of ${ }^{118} \mathrm{In}$. It was also seen by IS and $(t, p)$ reactions. We believe it is a $4^{+}$state.

Finally a $3.055 \mathrm{MeV}$ level was identified by Bjerregaard et al. and Cohen et al. The same authors have found a level at $3.136 \mathrm{MeV}$ given as $0^{+}$by the first group.

In Fig. 3 a level scheme of ${ }^{118} \mathrm{Sn}$ is presented. Only levels given by at least two groups are shown. Clearly much more experimental work must be done before any definitive and meaningful conclusions could be drawn from the properties of the low energy levels of this nucleus.

It is a pleasure to thank Dr. A. Moreira and his collaborators for their kind cooperation during the irradiations. This work was sponsored by C. N. Pq., B. N. D. E. and C. N. E. N.

\title{
Lebensdauern der Feinstrukturzustände $z^{4} F_{9 / 2}, z^{4} F_{7 / 2}, z^{4} G_{11 / 2}, z^{4} G_{9 / 2}$ und $y^{4} G_{11 / 2}$ im Kobalt-I-Spektrum
}

\author{
M. v. HARTROTT \\ Institut für Kernphysik der Technischen Universität Berlin \\ (Z. Naturforsch. 24 a, 1202-1209 [1969] ; eingegangen am 13. Mai 1969)
}

\begin{abstract}
Atomic lifetimes of 5 excited states in the Co-I spectrum are determined by a zero field levelcrossing experiment. Because of the complex spectrum of Co the radiation scattered by the atomic beam is carefully analysed to establish a correspondence of the observed signals to well defined finestructure levels. Since Co has only the one stable isotope ${ }^{59} \mathrm{Co}$, the influence of the hyperfinestructure splitting on the width of the depolarisation curves is estimated with special reference to the spectral distribution of the exciting radiation. The following values for lifetimes are deduced:

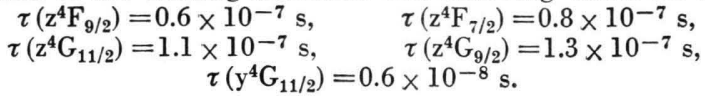

In dieser Arbeit wird eine Untersuchung der Winkelverteilung von Resonanzlicht freier Atome im schwachen Magnetfeld (HANLE-Effekt ${ }^{1}$, Nullfeldlevel-crossing ${ }^{2}$ ) zur Bestimmung von Lebensdauern an dem linienreichen Spektrum von Kobalt - einem Element der Eisengruppe - beschrieben. Bei dem vorliegenden Experiment stehen dem Vorzug weit-

Sonderdruckanforderungen erbeten an M. v. Hartrott, Institut für Kernphysik der Technischen Universität Berlin, D-1000 Berlin 37, Rondellstr. 5. gehender Unabhängigkeit der aus der Messung resultierenden Lebensdauern von der Dichte der streuenden Atome Schwierigkeiten gegenüber im Zusammenhang mit der Beobachtung intensitätsschwacher Resonanzlichtsignale. Die zur Verfügung stehende Lichtintensität wird beschränkt durch die hohe spektrale Auflösung der Resonanzstrahlung, die erfor-

1 W. Hanle, Z. Phys. 30, 93 [1924].

2 F. D. Colegrove, P. A. Franken, R. R. Levis u. R. H. SANDS, Phys. Rev. Letters 3, 420 [1959]. 